Y aquí llegamos al punto que nos interesa. Las obras de construcción fueron encargadas a un arquitecto o maestro de obras llamado en (el antiguo) checo Jan Spaniel, es decir Juan Español; a juzgar por la costumbre general de la época de llamar a los extranjeros, especialmente a arquitectos, por el país de su procedencia, fue -con la mayor probabilidad- español (cómo ejemplo nos servirá un tal Hans Vlach, o sea Juan Italiano) 9. La personalidad de este arquitecto Spaniel a quién le fue subordinado incluso un arquitecto italiano llamado Jeronym Vlach o sea Jerónimo Italiano, de Venecia (otro caso de la sustitución del apellido por la nacionalidad), igualmente activo a la sazón en Olomouc, queda lamentablemente anónima. Lo encontramos mencionado en dos documentos, en ambos casos en lengua checa, que nada aclaran, sólo testimonian.

Debido a que entre miembros del colegio jesuita en Olomouc había más españoles, puede suponerse que el arquitecto realmente fuera español. Con la mayor probabilidad se trataba del maestro de obras del área del ex convento minorita de San Francisco, que ya el obispo Prusínovský pensó convertir en edificios de la nueva Universidad, en 1570. Los datos dados a conocer por el historiador Maliva son importantes. El primer documento dice: «Tenemos noticias de que el maestro Jerónimo (en el original, en checo, Jeronym), quien está esculpiendo las piedras para el edificio de San Francisco, son demasiado pequeñas, de modo que no convendrá al edificio de San Francisco. Por esta razón se le ordenó rigurosamente que las esculpiese de tal forma que le indicase el maestro Juan Español (en el original checo od Jana Španiele)...». Y luego, aparece mencionado en otro documento lo siguiente: "Cuando el maestro Juan Español (en original checo: Jan Španiel) tasase, junto con otros, aquella obra de piedra que Jerónimo hiciera, deberías tú estar presente vigilando que no se nos engañase.... ${ }^{10}$.

Lo que queda es averiguar en archivos españoles si algún arquitecto o maestro de obras español de la misma época puede coincidir con las fechas indicadas.

Pavel ŠTĚPÁNEK

Universidad Palacky de Olomouc

\title{
NOTICIAS DOCUMENTALES SOBRE FRANCISCO MATARANA, VIDRIERO Y PINTOR
}

Francisco Matarana llegó a Cuenca en torno a 1577, procedía de Génova donde su hermano, el pintor Bartolomé Matarana 1, había firmado un contrato con don Fernando Carrillo de Mendoza, conde de Priego, para trabajar a su servicio ${ }^{2}$. En esa fecha Francisco debía de ser un

\footnotetext{
9 Josef Maliva, «K otázce autorstvi nejstaršich budov olomoucké univerzity" (En torno al problema del autor de los edificios más antiguos de la Universidad de Olomouc) - I. In: Cesty k výtvarnému uměni, Sborník prací Pedagogické fakulty Univerzity Palackého v Olomouci - 1980, SPN Praha, 1980, págs. 178 a 184, refiriéndose al Archivo Regional de Olomouc, de los días 27 de abril y el 10 de diciembre de 1574 que se refieren a la compra de casas vecinas y otros detalles.

10 J. Maliva, op. cit., nota 9, págs. 181 a 183, nota 16, Státní oblastni archiv v Olomouci (Archivo estatal regional de Olomouc) kop. 10, f. 177V, escrito y fechado en Kroměřŕž (residencia de veraneo del obispo de Olomouc), 15-11-1570 por el obispo Prusinovský a Adam Šlechta), f. 237, Kroměříž 8. XI. 1570.

1 Sobre Bartolomé Matarana véase: M. ${ }^{\mathrm{a}}$ Luz Rokiski Lázaro, "Notas sobre Bartolomé Matarana y Juan Gómez", Archivo Español de Arte, núm. 220, 1982, págs. 391, 392; "Bartolomé Matarana, vidriero», Archivo Español de Arte, núm. 9. 238, 1987, págs. 229, 230; “Noticias sobre el pintor Bartolomé Matarana en Cuenca», Cuenca, núm. 31/32, 1988, págs. 7-29.

2 López Torrijos, R., "Bartolomé Matarana y otros pintores italianos del siglo xviı", Archivo Español de Arte, núm. 202, 1978, págs. 184-186.
} 
muchacho joven, pues en el primer documento que poseemos sobre él, que data de 1578 , se le llama «el mozo» ${ }^{3}$.

En aquellos años se dieron cita en Cuenca varios arquitectos italianos, Juan Andrea Rodi, Pedro de Abril, Angel Baguti, Gion Louise Musante, Antonio Aprile y Alejandro Escala, atraídos todos por la obra del claustro de la catedral, en cuya construcción participaron ${ }^{4}$. Con ellos hay que suponer que se relacionaron los Matarana, de hecho Francisco fue testigo de Alejandro Escala en una carta de poder que éste otorgó el 31 de enero de $1604{ }^{5}$.

Matarana se estableció en Cuenca y ya no se movió de allí, salvo un viaje que efectuó a Valencia para realizar unas vidrieras. Vivió en una casa situada en el Corral de San Nicolás ${ }^{6}$.

Fue maestro vidriero de la catedral de Cuenca desde 1592 a $1631^{7}$, con un paréntesis de tres años (1598-1600) que coincidió con su larga estancia en Valencia. Sucedió en este puesto a la vidriera María Rodríguez y su quehacer era «el cuidado de renovar adereçar y recorrer las vidrieras». Desde 1592 hasta 1611 tuvo el mismo salario que su predecesora, seis mil maravedíes anuales ${ }^{8}$, excepto durante los años 1603 y 1605 , que recibió cinco mil maravedíes. A partir de 1611 se le rebajó su salario y hasta 1631 cobró cinco mil maravedíes ${ }^{9}$. Ahora bien, la fábrica de la catedral le pagaba además de su salario, aquellos trabajos que ejecutaba ${ }^{10}$.

Asimismo en la catedral, y en calidad de pintor ${ }^{11}$-aunque siempre se le encomendaron la-

3 ACC, Libro de fábrica, 1591-1621, fol. 206.

${ }_{4}$ M. ${ }^{a}$ Luz Rokiski Lázaro, "El claustro de la catedral de Cuenca en el siglo xvi. Sus arquitectos», Boletín de Información del Excmo. Ayuntamiento de Cuenca, núm. 82, 1975, págs. 23-34; Arquitectura del siglo xvi en Cuenca, Cuenca, 1985, págs. 192-201; Arquitectura del siglo xvi en Cuenca. Arquitectos, canteros y carpinteros, Cuenca, 1989, págs. 4-7, 23, 24, 45, 46, 75-79, 179.

5 AHPC, Tomas Pardo, 1602-1605 (752), fol. 1131.

6 M. ${ }^{a}$ Luz Rokiski Lázaro, «Bartolomé Matarana, vidriero», pág. 229.

7 En esos años también trabajaron otros vidrieros. En 1599 el canónigo obrero anota la siguiente partida: «doscientos y sesenta y un reales y un quartillo que pago a Jusephe de la Via maestro de vidrieras los quales fueron por noventa y cinco palmos de vidrieras que hizo para las ventanas de la capilla Nueva". Durante los años 1620-1621 el vidriero Juan Lucas reparó las vidrieras de la sala capitular y en 1622-1623 se pagó 21.570 maravedíes "a Vicente Ferrer vidriero natural de Valencia por tantos lo monto una quenta de las vidrieras que hiço en esta yglesia y jornales de otras que reparo y materiales que puso" (ACC, Libro de fábrica, 1591-1621, fol. 128v; 1622-1674, fols. 16, 458v).

8 «Una peticion de Francisco Matarana maestro de vidrieras le asinaron de salario 6.000 maravedies. Este dia se leyo una petición dada por parte de Francisco Matarana maestro de vidrieras en que pidió le mandasen librar el salario que el señor abbad de Santiago le avia ofrescido desde el principio deste año por quanto avia servido y adereçado las vidrieras de la iglesia y leyda los dichos señores dean y cabildo mandaron se le libren seys mill maravedies que se han acostumbrado dar a los semejantes maestros que a tenido la iglesia por el año pasado y para adelante le asinaron de salario seys mill maravedies» (ACC, Actas capitulares, 1592, fol. 105v).

9 ACC, Libro de fábrica, 1591-1621, fols. 48v, 68, 76v, 99, 161v, 172, 201v, 227, 232v, 260v, 298v, 338, 378v, 389, $414 \mathrm{v}, 429,452 ; 1622-1674$, fols. $9 \mathrm{v}, 37,65 \mathrm{v}, 93,120 \mathrm{v}$.

${ }^{10}$ En 1592 le entregaron 200 reales; en 1595, 60 reales; en 1601, 512 reales por reparar las vidrieras de la capilla mayor y las de las naves; en 1603, 3.400 maravedíes "para comprar ciertas vidrieras para la yglesia»; en 1604, 18.836 maravedíes; en 1606, 1.836 maravedíes "de aderezar la vidriera de la puerta que sale a la calle de San Pedro"; en 16111612, 3.672 maravedíes "por las vidrieras que hiço en la capilla mayor y adereçar y reparar otras de la yglesia"; en 16131614, 11.492 maravedíes; en 1615- 1616, 12.392 maravedíes "por la vidriera que hiço para esta yglesia y reparos de otras»; en 1619, 7.106 maravedíes «de las vidrieras que hiço para la capilla mayor»; en 1626, "para la que hiço en la ventana de la yglesia" y en 1628-1629, "por una vidriera para la ventana del altar de Nuestra Señora del Sagrario" (ACC, Libro de fábrica, 1591-1621, fols. 21v, 69v, 165v, 167, 203v, 210, 233, 347, 385, 396, 435; 1622-1674, fols. 70, 100).

11 En estos años también se documenta la intervención del pintor Félix Rodríguez, al cual se le pagó 30 reales por «retocar el rostro de Nuestra Señora y Niño del Sagrario»; la del pintor Alonso de Mayorga, que «retocó» los lienzos del monumento de Jueves Santo; la de Jerónimo de Mayorga, que con motivo de las honras fúnebres que se celebraron a la muerte del papa Pablo V, pintó la tiara que se puso en el túmulo y que "por dorar el remate del arca del monumento y platear los blandones» le pagaron 545 reales y 24 maravedíes; la del pintor Cristóbal Fernández, que recibió 200 reales "por reparar los blandones plateados" y la de Cristóbal García Salmerón que cobró 180 reales "por el retrato de pintura que hizo del beato Nuño de Fuente Encalada" (ACC, Libro de fábrica, 1591-1621, fols. 392, 456, 462; 1622-1674, fols. $14,149 v)$. 
bores menores ${ }^{12}$-, Matarana barnizó y doró el monumento que se ponía el Jueves Santo ${ }^{13}$; doró y "refrescó» un Crucifijo de plata que había en la nave de los Reyes ${ }^{14}$ y pintó las rejas de hiero que se pusieron en dos ventanas del coro ${ }^{15}$ así como veintiséis farolas para «las luminarias» que se hicieron con motivo de las fiestas de San Julián que se celebraron en $1630{ }^{16}$.

Con su hermano Bartolomé y con los pintores Quilez Moreno y Fernando de Mayorga policromó el retablo de la iglesia parroquial de Almendros (Cuenca). A causa de esta obra, en 1604 entabló un pleito contra la viuda del pintor Fernando de Mayorga, pues en esa fecha todavía no le habían pagado ${ }^{17}$.

Cuando en 1597 su hermano Bartolomé marchó a Valencia para pintar el colegio del Corpus Christi, él le acompañó y se encargó de hacer las vidrieras. También en Valencia puso las vidrieras del palacio arzobispal, las de la casa de la Huerta y las del convento de los capuchinos de la Sangre de Cristo ${ }^{18}$.

Francisco Matarana debió de morir a principios de 1632, pues en ese año su nombre no aparece citado en el libro de fábrica de la catedral. En 1634, tras dos años en los que no hubo maestro vidriero en la catedral, el cabildo nombró a Juan Bautista Bola ${ }^{19}$.

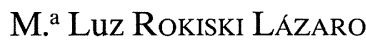
Universidad Politécnica de Madrid

12 En 1611-1612 se le pagan 18 reales «de un adereço que hiço para los gigantes»; en 1620-1621, 66 reales "por enbarniçar los rostros de los gigantes"; en 1622-1623, 45 reales "por enbarniçar los rostros de los gigantes y otras cosas"; en 1626 repara los rostros de los gigantes y lo vuelve a hacer de nuevo en 1630-1631 cobrando en esta ocasión 3.400 maravedíes (ACC, Libro de fábrica, 1591-1621, fols. 347, 455v; 1622-1674, fols. 12v, 68v, 123v).

13 En 1578 le entregan 16.116 maravedíes «de ciento cinco dias e medio que se ocupo en dorar y pintar la obra del monumento a quatro reales e medio cada un dia"; en 1620 se le encarga "dar el barniz y dorar las varandillas y bolas" y en 1624, "dar negro a unas tablas» (ACC, Libro de fábrica, 1548-1590, fol. 206; 1591-1621, fol. 462; 1622-1674, fol. 39v).

14 En 1601 le dieron 594 reales «doscientos quarenta y quatro de oro y lo demas por su travajo y jornal de quarenta y tres dias que se ocupo». En 1620 procedió a "limpiar el Cristo y molduras del crucero" (ACC, Libro de fábrica, 15911621 , fols. $165 \mathrm{v}, 166,463 \mathrm{v})$.

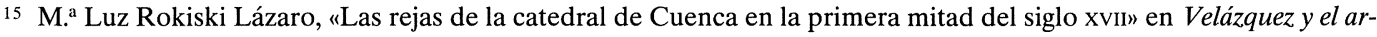
te de su tiempo, CSIC, 1991, pág. 392:

16 ACC, Libro de fábrica, 1622-1674, fol.124.

17 El 29 de marzo de 1604 firma un poder al procurador Juan Lozano para que cobre a la viuda del pintor Fernando de Mayorga lo que «monto la pintura que hize en una pieza de sagrario para la yglesia de la villa de Almendros»; y el 12 de mayo de ese mismo año, Catalina Díaz, viuda de Fernando de Mayorga, da un poder al procurador Juan del Val para que se ocupe del pleito que ha entablado contra ella Matarana (AHPC, Inocencio Pardo, 1603-1606 (648), fols. 335, 343). M. ${ }^{\mathrm{a}}$ Luz Rokiski Lázaro, "Noticias sobre el pintor Bartolomé Matarana en Cuenca», págs. $20,21$.

18 Fernando Benito, La arquitectura del colegio del patriarca y sus artífices, Valencia 1981, pág. 121.

19 ACC, Libro de fábrica, 1622-1674, fol. 171v. 